\title{
Pre-harvest Modulation of N-3 Long-chain Polyunsaturated Fatty Acids in Rainbow Trout Meat for Human Consumption
}

\author{
Yoshinaga $\mathbf{H}^{1}$, Ushio $\mathbf{H}^{1 *}$, Haga $\mathrm{Y}^{2}$ and Satoh $\mathrm{S}^{2}$
}

${ }^{1}$ Department of Aquatic Bioscience, Graduate School of Agricultural and Life Sciences, The University of Tokyo, Tokyo, Japan ${ }^{2}$ Department of Marine Biosciences, Tokyo University of Marine Science and Technology, Tokyo, Japan

\begin{abstract}
Since post-harvest improvement of food quality depends on the pre-harvest stage, controlling food quality at the pre-harvest stage is being recognized as an important aspect of food processing technology. $n-3$ Long-chain polyunsaturated fatty acids ( $n-3$ LCPUFAs) are considered important factors in the suppression of cardiovascular disease and development of the infant brain and visual functions. Fish meat generally contains a larger amount of $n-3$ LCPUFAs than meat from terrestrial animals, but the amount of n-3 LCPUFAs in fish meat depends on their dietary fatty acid intake. In order to supply n-3 LCPUFAs to consumers, we developed a finishing-up method, through a 4-day lysine-deficient diet feeding for rainbow trout (Oncorhynchus mykiss) meat. This 4-day lysine deficiency did not affect fish body weight, while significantly increased the total lipid content in the muscle tissue. In addition, docosahexaenoic acid and total n-3 fatty acid contents increased significantly in the meat throughout the 4-day finishing treatment. We concluded that the finishing-up method using short-term lysine-deficient diet feeding enables us to enrich fish meat with $n-3$ fatty acids for human consumption.
\end{abstract}

Keywords: $n$-3 Long-chain polyunsaturated fatty acids; Docosahexaenoic acid; Fish meat; Lipid content; Fatty acid content

Abbreviations: PUFA: Polyunsaturated Fatty Acid; n-3 LCPUFAs: n-3 Long-Chain Polyunsaturated Fatty Acids; Lys: Lysine; DHA: Docosahexaenoic Acid; EPA: Eicosapentaenoic Acid; DPA: Docosapentaenoic Acid; GC-FID: Gas Chromatography-Flame Ionization Detector; TAG: Triacylglycerol; TLC: Thin-Layer Chromatography; FAMEs: Fatty Acid Methyl Esters; HSI: Hepatosomatic Index; PL: Polar Lipid; PC: Phosphatidylcholine; PE: Phosphatidylethanolamine; PI: Phosphatidylinositol; PS: Phosphatidylserine; LPC: Lysophosphatidylcholine; NL: Nonpolar Lipid; SE: Sterol Ester; ST: Sterol; SFA: Saturated Fatty Acid; MUFA: Monounsaturated Fatty Acid; PUFA: Polyunsaturated Fatty Acid

\section{Introduction}

Polyunsaturated fatty acids (PUFAs) are recognized as important nutrients for human health. In particular, n-3 long-chain PUFAs (n-3 LCPUFAs), such as docosahexaenoic acid (DHA, 22:6n-3), docosapentaenoicacid (DPA, 22:5n-3), and eicosapentaenoic acid (EPA, 20:5n-3), are gaining attention. DHA is essential for the development of the infant brain and visual functions [1], and supplementation with DHA during pregnancy has been associated with reduced rates of both preterm and underweight births [2]. Previous studies showed that EPA and DHA supplementation improves cognitive function $[3,4]$. It has also been demonstrated that n-3 LCPUFAs have protective effects on the cardiovascular system: reducing blood pressure, blood viscosity, and the risk of cardiac arrhythmias [5-7].

The intake of fish meat and fish oil is associated with lower rates of cardiovascular disease [8] and hypertriglyceridemia [9], and fish oil consumption in pregnant woman is associated with a reduced risk of allergic disease in their offspring [10,11]. These beneficial effects of fish meat and fish oil are thought to be due to the high n-3 LCPUFA content of these foods. Fish meat contains higher concentrations of n-3 fatty acids than pork or beef [12-14], while n-3 fatty acid content in fish meat is strongly affected by the dietary fatty acid intake of the fish [15].

Since rainbow trout and other teleost fish species cannot desaturate fatty acids at the omega- 3 position, the body $n-3$ fatty acid content in these fish depends on their dietary fat intake. Currently, fish meat enriched with n-3 LCPUFAs requires mass consumption of fish meal and fish oil, increasing the total amount of fish harvested for eventual human consumption. It is, therefore, important to improve the efficiency of aquaculture techniques, and methods for accelerating n-3 LCPUFA synthesis from shorter n-3 fatty acids in fish and/or accumulating n-3 LCPUFAs preferentially in edible tissues.

Lysine (Lys) is an important amino acid for fish and a precursor of carnitine, which is used to transport fatty acids into mitochondria for oxidation. Several amino acids, including Lys, affect hormone secretion [16-18] and intracellular signaling pathways in fish [19]. Thus, dietary Lys levels probably affect energy metabolism including lipid accumulation in fish.

In the present study, we investigated the effects of short-term administration of Lys-deficient (Lys (-)) diets on rainbow trout (Oncorhynchus mykiss), focusing particularly on lipid and fatty acid content in the edible part of the fish, i.e., the skeletal muscle.

\section{Materials and Methods}

\section{Diet}

Control and Lys (-) diets were designed as shown in Table 1. Fish meal and corn gluten meal were used as the main protein source in control and Lys (-) diets, respectively. These diets were freeze-dried and stored at $4^{\circ} \mathrm{C}$ until use. The amino acid composition of each diet was analyzed using an amino acid analyzer L-8900 (Hitachi, Tokyo,

*Corresponding author: Hideki Ushio, Department of Aquatic Bioscience Graduate School of Agricultural and Life Sciences, The University of Tokyo, Yayoi, Bunkyo, Tokyo, 113-8657, Japan, Tel: +81-3-5841-5300, Fax: +81-3-5841-5300 E-mail: aushio@mail.ecc.u-tokyo.ac.jp

Received January 15, 2018; Accepted February 02, 2018; Published February 09, 2018

Citation: Yoshinaga H, Ushio H, Haga Y, Satoh S (2018) Pre-harvest Modulation of N-3 Long-chain Polyunsaturated Fatty Acids in Rainbow Trout Meat for Human Consumption. J Food Process Technol 9: 716. doi: 10.4172/2157-7110.1000716

Copyright: (c) 2018 Yoshinaga $\mathrm{H}$, et al. This is an open-access article distributed under the terms of the Creative Commons Attribution License, which permits unrestricted use, distribution, and reproduction in any medium, provided the original author and source are credited. 
Citation: Yoshinaga H, Ushio H, Haga Y, Satoh S (2018) Pre-harvest Modulation of N-3 Long-chain Polyunsaturated Fatty Acids in Rainbow Trout Meat for Human Consumption. J Food Process Technol 9: 716. doi: 10.4172/2157-7110.1000716

Page 2 of 7

Japan), and the fill rates of nutritionally important amino acids were calculated based on the results and the amino acid requirements of rainbow trout [20] (Table 2). The fatty acid composition of each diet

\begin{tabular}{|c|c|c|}
\hline Ingredients (\%) & Control & Lys (-) \\
\hline Anchovy meal & 45 & 5 \\
\hline Defatted soybean meal & - & 10 \\
\hline Blood meal & - & 4 \\
\hline Corn gluten meal & 5 & 33 \\
\hline Wheat flour & 17 & 17 \\
\hline Pre-gelatinized starch & 5 & 5 \\
\hline Fish oil & 5 & 7.4 \\
\hline Soy bean oil & 10 & 10 \\
\hline Vitamin mixture & 3 & 3 \\
\hline Choline chloride & 0.5 & 0.5 \\
\hline Vitamin E & 0.1 & 0.1 \\
\hline Mineral mixture & 1 & 1 \\
\hline Mono calcium phosphate & 1 & 1 \\
\hline Cellulose & 7.4 & 3 \\
\hline Total & 100 & 100 \\
\hline Moisture (\%) & 7.07 & 7.14 \\
\hline Crude protein (\%) & 32.2 & 33.0 \\
\hline Crude lipid (\%) & 22.0 & 22.7 \\
\hline Col $(\%)$ & & \\
\hline
\end{tabular}

Control: Control diet; Lys (-): Lysine-deficient diet

aitamin mixture composition (amounts in $\mathrm{kg}^{-1}$ ): vitamin A acetate, 2,420,000 IU; vitamin D3, 2,420,000 IU; vitamin K3, $6.05 \mathrm{~g}$; thiamin hydrochloride, 3.025 g: riboflavin, $3.63 \mathrm{~g}$; pyridoxine hydrochloride, $2.42 \mathrm{~g}$; cyanocobalamin, $0.006 \mathrm{~g}$ ascorbic acid, $368.902 \mathrm{~g}$ : niacin, $24.2 \mathrm{~g}$; calcium pantothenate, $6.05 \mathrm{~g}$; inositol, $121 \mathrm{~g}$; biotin, $0.363 \mathrm{~g}$; folic acid, $0.908 \mathrm{~g} ; p$-aminobenzoic acid, $3.025 \mathrm{~g}$. 'Mineral mixture composition (amounts in $\mathrm{kg}^{-1}$ ): sodium chloride, $50 \mathrm{~g}$; magnesium sulfate, $745 \mathrm{~g}$; iron (III) citrate $\mathrm{n}$-hydrate, $125 \mathrm{~g}$; trace element mixture, $50 \mathrm{~g}$; cellulose, $30 \mathrm{~g}$. (The trace element mixture contained (amounts in $\mathrm{kg}^{-1}$ ): zinc sulfate heptahydrate, $353 \mathrm{~g}$; manganese sulfate, $162 \mathrm{~g}$, copper (II) sulfate pentahydrate, $31 \mathrm{~g}$; aluminum chloride hexahydrate, $10 \mathrm{~g}$; cobalt chloride, $3 \mathrm{~g}$; potassium iodate, $1 \mathrm{~g}$; cellulose, $440 \mathrm{~g}$ ).

Table 1: Diet formulae in Lys-deficient feeding.

\begin{tabular}{|c|c|c|}
\hline Nutritionally important amino acid (\%) & Control & Lys (-) \\
\hline Threonine & 1.3 & 1.3 \\
\hline Valine & 1.7 & 1.6 \\
\hline Cysteine & 0.2 & 0.2 \\
\hline Methionine & 0.9 & 0.7 \\
\hline Isoleucine & 1.4 & 1.3 \\
\hline Leucine & 2.7 & 4.0 \\
\hline Tyrosine & 0.9 & 1.2 \\
\hline Phenylalanine & 1.4 & 1.7 \\
\hline Lysine & 2.3 & 1.3 \\
\hline Histidine & 0.9 & 0.7 \\
\hline Arginine & 1.8 & 1.4 \\
\hline Fill-rate of amino acids (\%) & Control & Lys (-) \\
\hline Threonine & 92.0 & 98.7 \\
\hline Valine & 137.6 & 134.0 \\
\hline Cysteine & 121.2 & 140.6 \\
\hline Methionine & 136.3 & 100.2 \\
\hline Isoleucine & 151.7 & 143.6 \\
\hline Leucine & 157.6 & 238.8 \\
\hline Tyrosine & 114.1 & 145.7 \\
\hline Phenylalanine & 112.9 & 146.1 \\
\hline Lysine & 112.6 & 61.7 \\
\hline Histidine & 144.6 & 119.2 \\
\hline Arginine & 133.3 & 103.1 \\
\hline
\end{tabular}

Amino acid contents (\% in diet) of control and lysine-deficient (Lys (-)) diets were obtained by amino acid analyzer, and fill-rates of amino acids were calculated by the amino acid contents and amino acid requirement in rainbow trout.

Table 2: Nutritionally important amino acid compositions of diets and adequacy for requirement of amino acids in rainbow trout.

\begin{tabular}{|c|c|c|}
\hline Fatty acids (\%) & Control & Lys (-) \\
\hline $14: 0$ & 2.71 & 2.08 \\
\hline $15: 0$ & 0.12 & 0.16 \\
\hline $16: 0$ & 14.23 & 12.96 \\
\hline $16: 1 n-9$ & 0.05 & 0.11 \\
\hline $16: 1 n-7$ & 2.89 & 2.57 \\
\hline $17: 0$ & 0.39 & 0.21 \\
\hline $18: 0$ & 3.37 & 3.14 \\
\hline $18: 1 n-9$ & 18.49 & 19.58 \\
\hline $18: 1 n-7$ & 1.78 & 1.63 \\
\hline $18: 2 n-6$ & 34.85 & 36.35 \\
\hline $18: 3 n-3$ & 3.65 & 3.53 \\
\hline $18: 3 n-9$ & 0.87 & 0.90 \\
\hline $20: 0$ & 0.25 & 0.23 \\
\hline $20: 1 n-9$ & 1.94 & 2.88 \\
\hline $20: 1 n-7$ & 1.27 & 1.41 \\
\hline $20: 2 n-6$ & 0.09 & 0.08 \\
\hline $20: 3 n-6$ & N.D. & N.D. \\
\hline $20: 4 n-6$ & 0.33 & 0.17 \\
\hline $20: 4 n-3$ & 0.24 & 0.27 \\
\hline $20: 5 n-3$ & 4.37 & 3.47 \\
\hline $22: 0$ & 0.18 & 0.19 \\
\hline $22: 1 n-11$ & 3.02 & 4.14 \\
\hline $22: 1 n-9$ & 0.42 & 0.51 \\
\hline $22: 4 n-3$ & 0.06 & 0.04 \\
\hline $22: 5 n-6$ & 0.11 & 0.05 \\
\hline $22: 5 n-3$ & 0.59 & 0.45 \\
\hline $22: 6 n-3$ & 3.74 & 2.90 \\
\hline $24: 1 n-9$ & N.D. & N.D. \\
\hline$\sum$ SFA & 21.24 & 18.97 \\
\hline$\sum$ MUFA & 29.86 & 32.83 \\
\hline$\sum$ PUFA & 48.90 & 48.20 \\
\hline$\sum n-3$ & 12.65 & 10.66 \\
\hline$\sum n-6$ & 35.38 & 36.65 \\
\hline
\end{tabular}

The fatty acid composition of each diet was measured with a gas chromatography-flame ionization detector. Control, control diet; Lys (-), lysinedeficient diet; SFA, saturated fatty acid; MUFA, monounsaturated fatty acid; PUFA, polyunsaturated fatty acid; n-3, n-3 fatty acid; n-6, n-6 fatty acid; N.D., Not Detected

Table 3: Fatty acid compositions in control and Lys-deficient diets.

was measured with a gas chromatography-flame ionization detector (GC-FID, GC-2014, Shimadzu, Kyoto, Japan), under conditions described later. We confirmed that combinations of soybean oil and fish oil provided similar fatty acid compositions in both diets (Table 3).

\section{Fish and experimental conditions}

Rainbow trout $(\mathrm{n}=15)$ were maintained under a 12:12 h lightdark photoperiod at approximately $10^{\circ} \mathrm{C}$, in a tank equipped with a recirculating system, and fed the control diet for approximately one month. In the experimental stage, fish were fed the Lys (-) diet up to four days (experimental feeding). The experimental period of four days was decided because a slight loss in body weight was observed after six days in the preliminary trials. Fish were fed until satiation during both periods. Five individuals each were collected without treatment on Day 0 , Day 2, and Day 4 of the experimental feeding period.

All animal care and use guidelines were followed according to the institutional protocol and approved by the University of Tokyo (P17093, approved on Aug 16, 2017).

\section{Total lipid and triacylglycerol contents}

Total lipid fractions were extracted from the liver and muscle 
Citation: Yoshinaga H, Ushio H, Haga Y, Satoh S (2018) Pre-harvest Modulation of N-3 Long-chain Polyunsaturated Fatty Acids in Rainbow Trout Meat for Human Consumption. J Food Process Technol 9: 716. doi: 10.4172/2157-7110.1000716

Page 3 of 7

of rainbow trout according to the method of Bligh and Dyer [21]. The total lipid content of each extracted solution was determined gravimetrically. Triacylglycerol (TAG) content was measured using a Triglyceride E-test Wako kit (Wako Pure Chemical Industries, Osaka, Japan).

\section{Lipid class composition}

Lipid class compositions in the muscle and liver tissues were determined through thin-layer chromatography (TLC). The extracted total lipids were spotted on glass TLC plates coated with silica gel 60 (Merck, Tokyo, Japan). A developing solvent mixture of chloroform/ methanol/water $(65: 30: 5, \mathrm{v} / \mathrm{v} / \mathrm{v})$ was used to separate polar lipids, and then a mixture of hexane/diethyl ether/acetic acid (80:20:1.5, v/v/v) was used to separate nonpolar lipids [22]. The plate was sprayed with $40 \%$ sulfuric acid and heated at about $100^{\circ} \mathrm{C}$. Images obtained by scanning plates were analyzed using ImageJ (Version 1.51 for Windows, National Institutes of Health, Bethesda, MD, USA).

\section{Fatty acid content}

Methanolic $\mathrm{NaOH}$ was added to tissue total lipid extracts and incubated for $10 \mathrm{~min}$ at $90^{\circ} \mathrm{C}$ for saponification. The saponification products were converted to methyl esters using boron trifluoride/ methanol and the resulting fatty acid methyl esters (FAMEs) were extracted with isooctane. The obtained FAMEs were analyzed in a gas chromatograph system GC-2014 with FID (Shimadzu, Kyoto, Japan) equipped with a Supelcowax-10 capillary GC column $(0.25 \mathrm{~mm}$ i.d. $\times 30$ $\mathrm{m}$, Supelco, Tokyo, Japan). Helium was used as a carrier gas at a column inlet pressure of $120 \mathrm{kPa}$. Column temperature was programmed to increase from $140^{\circ} \mathrm{C}$ to $180^{\circ} \mathrm{C}$ at a rate of $5^{\circ} \mathrm{C} / \mathrm{min}$, after initially holding at $140^{\circ} \mathrm{C}$ for $5 \mathrm{~min}$. Column temperature was then raised from $180^{\circ} \mathrm{C}$ to $240^{\circ} \mathrm{C}$ at a rate of $1.2^{\circ} \mathrm{C} / \mathrm{min}$, before being kept at $240^{\circ} \mathrm{C}$ for 10 min. Methyl tricosanoate (23:0) was used as an internal standard, and methyl palmitate (16:0), methyl stearate (18:0), methyl oleate (18:1n9), methyl arachidonate (20:4n-6), methyl eicosapentaenoate (20:5n3 ), and methyl docosahexaenoate (22:6n-3) were used as standards. Fatty acids were identified based on the peaks of these standards and equivalent chain length values, together with our laboratory retention time databases confirmed by GC-mass spectrometry analyses.

\section{Phosphoric acid content}

To quantify phospholipids, phosphoric acid contents in total lipid extracts were measured according to the Fiske and Subbarow [23], Bartlett [24] methods. Potassium dihydrogen phosphate solution was used as a standard. A $5 \mathrm{M}$ solution of sulfuric acid was added to the aliquoted total lipid extracts. The mixtures were incubated at $150^{\circ} \mathrm{C}$ for $3 \mathrm{~h}$ in a wet ashing procedure. After cooling, 30\% hydrogen peroxide was added to the mixtures, followed by incubation at $150^{\circ} \mathrm{C}$ for 1.5 h. A $0.22 \%$ solution of aqueous ammonium molybdate was then added, and the mixtures were vortexed. A Fiske-Subbarow reagent was immediately poured into the mixtures, followed by incubation in boiling water for $7 \mathrm{~min}$. Absorbances of the mixtures were measured at $830 \mathrm{~nm}$.

\section{Statistical analysis}

In all data, outliers in each group were excluded by SmirnovGrubbs test $(p<0.05)$. Dunnett's test was used for multiple comparisons of all variables between the initial group (Day 0) and groups fed the Lys (-) diet (Day 2 and Day 4). Values with $p<0.05$ were considered statistically significant. Statistical analyses were performed using $\mathrm{R}$ software (Version 3.3.2).

\section{Results}

\section{Condition factor, hepatosomatic index and total lipid content}

No significant difference was noted in condition factor among the initial (Day 0) and Lys (-) groups (Day 2 and Day 4), while hepatosomatic index (HSI) on Day 4 was significantly higher than that on Day 0 (Table 4). Total lipid content in the muscle was significantly elevated on Day $4(3.26 \% \pm 0.41)$, about 2 -fold the level on Day $0(1.72 \%$ $\pm 0.27)$. The liver total lipid content on Day $4(4.31 \% \pm 0.25)$ was also significantly higher than that on Day $0(3.33 \% \pm 0.11)$.

\section{Lipid class compositions in muscle and liver}

No significant difference was noted in lipid class compositions in the muscle among the initial and Lys (-) groups (Table 5). Phospholipid content and proportions of phosphatidylcholine (PC), phosphatidylethanolamine (PE), phosphatidylinositol (PI), phosphatidylserine (PS), and lysophosphatidylcholine (LPC) in the muscle did not change during the feeding trials. There was no significant difference in the proportions of sterol ester (SE), triacylglycerol (TAG),

\begin{tabular}{|c|c|c|c|}
\hline \multirow{2}{*}{ Variables } & \multirow{2}{*}{$\begin{array}{c}\text { Control } \\
\text { Day } 0\end{array}$} & \multicolumn{2}{|c|}{ Lys (-) } \\
\hline & & Day 2 & Day 4 \\
\hline Standard length $(\mathrm{cm})$ & $25.60 \pm 0.55$ & $26.06 \pm 0.58$ & $24.40 \pm 0.90$ \\
\hline Body weight (g) & $257.28 \pm 14.95$ & $290.06 \pm 15.59$ & $236.76 \pm 28.31$ \\
\hline Condition factor ${ }^{\mathrm{a}}$ & $1.53 \pm 0.08$ & $1.65 \pm 0.09$ & $1.60 \pm 0.04$ \\
\hline $\mathrm{HSI}^{\mathrm{b}}$ & $1.27 \pm 0.14$ & $1.60 \pm 0.14$ & $1.70 \pm 0.09^{*}$ \\
\hline \multicolumn{4}{|c|}{ Total lipid content ( $\%$ wet tissue) } \\
\hline Muscle & $1.72 \pm 0.27$ & $1.93 \pm 0.38$ & $3.26 \pm 0.41^{*}$ \\
\hline Liver & $3.33 \pm 0.11$ & $3.59 \pm 0.12$ & $4.31 \pm 0.25^{*}$ \\
\hline \multicolumn{4}{|c|}{$\begin{array}{l}\text { Values are means } \pm \text { SEM }\left(n=5,{ }^{*} p<0.05\right) \\
\text { Control: Control diet; Lys }(-) \text { : Lysine-deficient diet } \\
\text { aCondition factor=[body weight } \times 100] / \text { standard length } \\
{ }^{b} \mathrm{HSI}: \text { Hepatosomatic index=liver weight } / \text { body weight } \times 100\end{array}$} \\
\hline
\end{tabular}

Table 4: Standard length $(\mathrm{cm})$, body weight $(\mathrm{g})$, hepatosomatic index (HSI) condition factor, and total lipid content in tissue (\% wet tissue) in Lys-deficient trial.

\begin{tabular}{|c|c|c|c|}
\hline \multirow{2}{*}{ Variables } & \multirow{2}{*}{$\begin{array}{c}\text { Control } \\
\text { Day } 0\end{array}$} & \multicolumn{2}{|c|}{ Lys (-) } \\
\hline & & Day 2 & Day 4 \\
\hline \multicolumn{4}{|c|}{ Phospholipid content (mol/g wet tissue) } \\
\hline Phospholipid & $13.90 \pm 0.41$ & $17.08 \pm 0.85$ & $18.18 \pm 2.11$ \\
\hline \multicolumn{4}{|c|}{ PL class composition $(\%)$} \\
\hline PE & $24.69 \pm 1.18$ & $22.77 \pm 0.37$ & $23.50 \pm 0.06$ \\
\hline $\mathrm{PI}$ & $4.89 \pm 0.56$ & $4.74 \pm 0.09$ & $4.34 \pm 0.19$ \\
\hline $\mathrm{PC}$ & $59.19 \pm 0.92$ & $59.23 \pm 0.79$ & $62.32 \pm 1.41$ \\
\hline PS & $7.94 \pm 1.15$ & $9.20 \pm 1.16$ & $6.95 \pm 1.57$ \\
\hline LPC & $3.28 \pm 0.35$ & $4.76 \pm 0.95$ & $3.19 \pm 0.59$ \\
\hline \multicolumn{4}{|c|}{ NL class composition $(\%)$} \\
\hline SE & $12.15 \pm 2.29$ & $11.89 \pm 1.39$ & $10.75 \pm 1.51$ \\
\hline TAG & $74.75 \pm 2.97$ & $71.89 \pm 4.40$ & $78.99 \pm 3.61$ \\
\hline ST & $15.20 \pm 2.32$ & $16.22 \pm 3.08$ & $10.26 \pm 2.19$ \\
\hline \multicolumn{4}{|c|}{ TAG content ( $\%$ wet tissue) } \\
\hline TAG & $1.13 \pm 0.15$ & $1.68 \pm 0.17^{*}$ & $2.67 \pm 0.14^{*}$ \\
\hline \multicolumn{4}{|c|}{$\begin{array}{l}\text { Lipid class composition of muscle was determined through thin-layer } \\
\text { chromatography, and TAG contents were measured by using a Triglyceride } \\
\text { E-test Wako kit (Wako Pure Chemical Industries, Osaka, Japan). } \\
\text { Phospholipid contents in muscle were measured according to Fiske/Subbarow } \\
\text { and Bartlett methods [23,24]. } \\
\left.\text { Values are means } \pm \text { SEM ( } n=5,{ }^{*} p<0.05\right) \text {. } \\
\text { Control: Control diet; Lys (-): Lysine-deficient diet; PL: Polar lipid; NL: Non- } \\
\text { polar lipid; PE: Phosphatidylethanolamine; PI: Phosphatidylinositol; PC: } \\
\text { Phosphatidylcholine; PS: Phosphatidylserine; LPC: Lysophosphatidylcholine; } \\
\text { SE: Sterol ester; TAG: Triacylglycerol; ST: Sterol }\end{array}$} \\
\hline
\end{tabular}

Table 5: Lipid class composition (\%), phospholipid content (mol/g wet tissue), and triacylglycerol content (\% wet tissue) in muscle. 
Citation: Yoshinaga H, Ushio H, Haga Y, Satoh S (2018) Pre-harvest Modulation of N-3 Long-chain Polyunsaturated Fatty Acids in Rainbow Trout Meat for Human Consumption. J Food Process Technol 9: 716. doi: 10.4172/2157-7110.1000716

Page 4 of 7

and sterol (ST) among the initial and Lys (-) groups. On the other hand, TAG content in the muscle gradually increased through the experimental feeding period $(p<0.05)$.

There was no significant difference in the liver phospholipid content among the three groups (Table 6). Significant differences were

\begin{tabular}{|c|c|c|c|}
\hline \multirow{2}{*}{ Variables } & Control & \multicolumn{2}{|c|}{ Lys (-) } \\
\cline { 2 - 4 } & Day 0 & Day 2 & Day 4 \\
\hline Phospholipid & $50.75 \pm 2.83$ & $46.45 \pm 3.56$ & $55.11 \pm 6.27$ \\
\hline \multicolumn{4}{|c|}{ PL class composition (\%) } \\
\hline PE & $22.84 \pm 0.36$ & $21.13 \pm 0.71$ & $25.26 \pm 1.12$ \\
\hline PI & $5.12 \pm 0.20$ & $4.47 \pm 0.35$ & $4.99 \pm 0.25$ \\
\hline PC & $59.10 \pm 1.61$ & $63.36 \pm 1.02$ & $59.70 \pm 1.45$ \\
\hline PS & $6.41 \pm 0.87$ & $6.01 \pm 0.50$ & $7.22 \pm 1.80$ \\
\hline LPC & $5.69 \pm 0.25$ & $5.04 \pm 0.28$ & $4.02 \pm 0.24^{*}$ \\
\hline \multicolumn{4}{|c|}{ NL class composition (\%) } \\
\hline SE & $36.81 \pm 1.98$ & $33.59 \pm 1.98$ & $36.47 \pm 5.48$ \\
\hline TAG & $33.77 \pm 3.07$ & $39.71 \pm 4.40$ & $42.61 \pm 5.25$ \\
\hline ST & $29.42 \pm 3.00$ & $26.70 \pm 2.94$ & $20.92 \pm 2.33$ \\
\hline \multicolumn{4}{|c|}{ TAG content (\% wet tissue) } \\
\hline TAG & $2.01 \pm 0.16$ & $1.87 \pm 0.16$ & $3.23 \pm 0.29^{*}$ \\
\hline
\end{tabular}

Lipid class composition of liver was determined through thin-layer

chromatography, and TAG contents were measured by using a Triglyceride

E-test Wako kit (Wako Pure Chemical Industries, Osaka, Japan). Phospholipid contents in muscle were measured according to Fiske/Subbarow and Bartlett methods [23,24].

Values are means $\pm \operatorname{SEM}\left(n=5,{ }^{*} p<0.05\right)$

Control: Control diet; Lys (-): Lysine-deficient diet; PL: Polar lipid; NL: Non-

polar lipid; PE: Phosphatidylethanolamine; PI: Phosphatidylinositol; PC

Phosphatidylcholine; PS: Phosphatidylserine; LPC: Lysophosphatidylcholine; SE: Sterol ester; TAG: Triacylglycerol; ST: Sterol

Table 6: Lipid class composition (\%), phospholipid content (mol/g wet tissue), and triacylglycerol content (\% wet tissue) in liver.

\begin{tabular}{|c|c|c|c|}
\hline \multirow{2}{*}{ Variables } & \multirow{2}{*}{$\begin{array}{c}\text { Control } \\
\text { Day } 0\end{array}$} & \multicolumn{2}{|c|}{ Lys (-) } \\
\hline & & Day 2 & Day 4 \\
\hline $14: 0$ & $0.216 \pm 0.048$ & $0.282 \pm 0.072$ & $0.302 \pm 0.037$ \\
\hline $15: 0$ & $0.022 \pm 0.004$ & $0.035 \pm 0.003$ & $0.052 \pm 0.013^{*}$ \\
\hline 16:0 & $2.089 \pm 0.294$ & $2.519 \pm 0.374$ & $2.835 \pm 0.341$ \\
\hline $16: 1 n-9$ & $0.015 \pm 0.005$ & $0.022 \pm 0.007$ & $0.040 \pm 0.012$ \\
\hline $16: 1 n-7$ & $0.308 \pm 0.071$ & $0.418 \pm 0.116$ & $0.498 \pm 0.082$ \\
\hline $17: 0$ & $0.019 \pm 0.003$ & $0.029 \pm 0.003$ & $0.034 \pm 0.007$ \\
\hline $18: 0$ & $0.566 \pm 0.089$ & $0.699 \pm 0.114$ & $0.754 \pm 0.055$ \\
\hline $18: 1 n-9$ & $2.068 \pm 0.503$ & $2.750 \pm 0.706$ & $3.015 \pm 0.301$ \\
\hline $18: 1 n-7$ & $0.183 \pm 0.062$ & $0.337 \pm 0.072$ & $0.363 \pm 0.040$ \\
\hline $18: 2 n-6$ & $1.801 \pm 0.422$ & $2.711 \pm 0.721$ & $2.452 \pm 0.495$ \\
\hline $18: 3 n-3$ & $0.158 \pm 0.032$ & $0.248 \pm 0.064$ & $0.243 \pm 0.028$ \\
\hline $18: 3 n-9$ & $0.041 \pm 0.011$ & $0.061 \pm 0.020$ & $0.065 \pm 0.010$ \\
\hline $20: 0$ & $0.021 \pm 0.005$ & $0.029 \pm 0.009$ & $0.029 \pm 0.003$ \\
\hline $20: 1 n-9$ & $0.307 \pm 0.093$ & $0.416 \pm 0.123$ & $0.373 \pm 0.070$ \\
\hline $20: 1 n-7$ & $0.232 \pm 0.059$ & $0.325 \pm 0.082$ & $0.311 \pm 0.028$ \\
\hline $20: 2 n-6$ & $0.150 \pm 0.036$ & $0.179 \pm 0.046$ & $0.193 \pm 0.020$ \\
\hline $20: 3 n-6$ & $0.088 \pm 0.022$ & $0.103 \pm 0.016$ & $0.117 \pm 0.010$ \\
\hline $20: 4 n-6$ & $0.138 \pm 0.001$ & $0.178 \pm 0.011$ & $0.208 \pm 0.034$ \\
\hline $20: 4 n-3$ & $0.065 \pm 0.010$ & $0.089 \pm 0.019$ & $0.092 \pm 0.014$ \\
\hline $20: 5 n-3$ & $0.421 \pm 0.032$ & $0.520 \pm 0.043$ & $0.533 \pm 0.051$ \\
\hline $22: 0$ & $0.009 \pm 0.002$ & $0.016 \pm 0.003$ & $0.031 \pm 0.013$ \\
\hline $22: 1 n-11$ & $0.345 \pm 0.106$ & $0.465 \pm 0.132$ & $0.427 \pm 0.066$ \\
\hline $22: 1 n-9$ & $0.053 \pm 0.014$ & $0.071 \pm 0.018$ & $0.066 \pm 0.006$ \\
\hline $22: 4 n-3$ & $0.009 \pm 0.003$ & $0.020 \pm 0.002^{*}$ & $0.033 \pm 0.003^{*}$ \\
\hline $22: 5 n-6$ & $0.053 \pm 0.007$ & $0.084 \pm 0.012$ & $0.102 \pm 0.018^{*}$ \\
\hline $22: 5 n-3$ & $0.154 \pm 0.017$ & $0.228 \pm 0.033$ & $0.225 \pm 0.020$ \\
\hline
\end{tabular}

\begin{tabular}{|c|c|c|c|}
\hline $22: 6 n-3$ & $2.984 \pm 0.111$ & $3.515 \pm 0.169$ & $3.698 \pm 0.276^{*}$ \\
\hline $24: 1 n-9$ & $0.012 \pm 0.005$ & $0.013 \pm 0.004$ & $0.019 \pm 0.008$ \\
\hline$\sum$ SFA & $2.942 \pm 0.442$ & $3.615 \pm 0.577$ & $4.013 \pm 0.430$ \\
\hline$\sum$ MUFA & $3.524 \pm 0.861$ & $4.818 \pm 1.246$ & $5.094 \pm 0.541$ \\
\hline$\sum$ PUFA & $6.114 \pm 0.596$ & $7.933 \pm 1.062$ & $8.353 \pm 0.683$ \\
\hline$\sum n-3$ & $3.827 \pm 0.150$ & $4.562 \pm 0.268$ & $4.824 \pm 0.382^{*}$ \\
\hline$\sum n-6$ & $2.246 \pm 0.485$ & $3.256 \pm 0.774$ & $3.264 \pm 0.321$ \\
\hline
\end{tabular}

Fatty acid contents of muscle were measured with a gas chromatography-flame ionization detector.

Values are means $\pm \operatorname{SEM}\left(\mathrm{n}=5,{ }^{*} p<0.05\right)$.

Control: Control diet; Lys (-): Lysine-deficient diet; SFA: Saturated fatty acid;

MUFA: Monounsaturated fatty acid; PUFA: Polyunsaturated fatty acid; n-3: n-3 fatty acid; n-6: $n-6$ fatty acid.

Table 7: Fatty acid content $(\mathrm{mg} / \mathrm{g})$ in muscle of rainbow trout from Lys-deficient trial.

not observed in lipid class levels in the liver during the feeding trials. No significant difference was noted in the proportions of nonpolar lipids, SE, TAG, and ST levels among the initial and Lys (-) groups, while TAG content in the liver on Day 4 was significantly higher than that on Day 0.

\section{Muscle fatty acid content}

Some fatty acids in muscle significantly increased in groups of Lys $(-)$ diet-fed fish, compared to the initial group (Table 7). Contents of 22:6n-3 and 22:4n-3 on Day 4 were higher than those on Day $0(p<0.05)$. Total amount of n-3 fatty acids on Day 4 was also significantly higher than that on Day 0 in the muscle.

\section{Liver fatty acid content}

Contents of some fatty acids in liver of rainbow trout changed during the course of the Lys (-) feeding period (Table 8). Total saturated fatty acid (SFA) and total monounsaturated fatty acid (MUFA) contents in the liver on Day 4 were significantly higher than those on Day 0, respectively. Level of 20:0 was significantly higher on Day 4 than on Day 0. Levels of 16:1n-7, 18:1n-9, 18:2n-6, and 18:3n-6 were higher on Day 4 than on Day 0 . No significant change was noted in the liver fatty acid content between Day 2 and Day 0, except that 20:2n-6 level was higher on Day 2 than on Day 0.

\section{Discussion}

In this study, the effects of short-term Lys (-) diet feeding on lipid compositions in rainbow trout tissues were investigated to develop a method for enriching fish meat with n-3 LCPUFAs. Lys-deficient feeding for four days successfully increased total n-3 fatty acid and DHA contents in fish meat.

Under short-term Lys-deficiency, no significant failure in condition factor was observed. In long-term feeding, a diet based mainly on plant protein leads to inadequate intake of nutritionally important amino acids and loss of body weight $[25,26]$. The experimental period of this study was too short to cause such a body weight loss. Total lipid content in muscle on Day 4 was significantly higher than that on Day 0 , suggesting that short-term Lys-deficient feeding had increased lipid content in rainbow trout muscle without body weight loss. We have also found that liver lipid content and HSI also increased throughout the experimental feeding period, and that the increase in lipid content probably contributed to the HSI increment.

Previous studies have shown that longer Lys-deficient feeding periods of 14 and 25 days increased lipid content in the livers of rats $[27,28]$. In Atlantic salmon, 3-month Lys-deficiency also caused an increase in the liver lipid content [29]. Katsumata et al. [30] have 


\begin{tabular}{|c|c|c|c|}
\hline \multirow{2}{*}{ Variables } & \multirow{2}{*}{$\begin{array}{c}\text { Control } \\
\text { Day } 0\end{array}$} & \multicolumn{2}{|c|}{ Lys (-) } \\
\hline & & Day 2 & Day 4 \\
\hline $14: 0$ & $0.232 \pm 0.012$ & $0.237 \pm 0.005$ & $0.275 \pm 0.018$ \\
\hline 15:0 & $0.032 \pm 0.004$ & $0.031 \pm 0.002$ & $0.024 \pm 0.002$ \\
\hline 16:0 & $3.867 \pm 0.353$ & $3.142 \pm 0.164$ & $4.162 \pm 0.434$ \\
\hline $16: 1 n-9$ & $0.052 \pm 0.004$ & $0.075 \pm 0.011$ & $0.074 \pm 0.006$ \\
\hline $16: 1 n-7$ & $0.365 \pm 0.038$ & $0.263 \pm 0.019$ & $0.774 \pm 0.101^{*}$ \\
\hline $17: 0$ & $0.030 \pm 0.001$ & $0.030 \pm 0.003$ & $0.033 \pm 0.003$ \\
\hline 18:0 & $1.569 \pm 0.110$ & $2.045 \pm 0.239$ & $2.057 \pm 0.274$ \\
\hline $18: 1 n-9$ & $2.586 \pm 0.248$ & $1.970 \pm 0.134$ & $4.416 \pm 0.556^{*}$ \\
\hline $18: 1 n-7$ & $0.396 \pm 0.051$ & $0.532 \pm 0.018$ & $0.433 \pm 0.025$ \\
\hline $18: 2 n-6$ & $1.922 \pm 0.150$ & $2.138 \pm 0.264$ & $2.705 \pm 0.181^{*}$ \\
\hline $18: 3 n-6$ & $0.049 \pm 0.005$ & $0.052 \pm 0.004$ & $0.080 \pm 0.007^{*}$ \\
\hline $18: 3 n-3$ & $0.096 \pm 0.016$ & $0.106 \pm 0.009$ & $0.119 \pm 0.013$ \\
\hline $18: 3 n-9$ & $0.024 \pm 0.004$ & $0.019 \pm 0.003$ & $0.029 \pm 0.003$ \\
\hline $20: 0$ & $0.044 \pm 0.005$ & $0.053 \pm 0.002$ & $0.071 \pm 0.006^{*}$ \\
\hline $20: 1 n-9$ & $0.123 \pm 0.008$ & $0.152 \pm 0.029$ & $0.204 \pm 0.021$ \\
\hline $20: 1 n-7$ & $0.471 \pm 0.073$ & $0.674 \pm 0.066$ & $0.583 \pm 0.013$ \\
\hline $20: 2 n-9$ & $0.044 \pm 0.015$ & $0.031 \pm 0.004$ & $0.070 \pm 0.008$ \\
\hline $20: 2 n-6$ & $0.566 \pm 0.033$ & $1.035 \pm 0.150^{*}$ & $0.614 \pm 0.044$ \\
\hline $20: 3 n-9$ & $0.035 \pm 0.009$ & $0.054 \pm 0.010$ & $0.051 \pm 0.009$ \\
\hline $20: 3 n-6$ & $0.540 \pm 0.123$ & $0.735 \pm 0.114$ & $0.817 \pm 0.050$ \\
\hline $20: 4 n-6$ & $0.909 \pm 0.126$ & $1.303 \pm 0.280$ & $0.543 \pm 0.228$ \\
\hline $20: 4 n-3$ & $0.094 \pm 0.011$ & $0.083 \pm 0.010$ & $0.080 \pm 0.004$ \\
\hline $20: 5 n-3$ & $0.630 \pm 0.065$ & $0.587 \pm 0.042$ & $0.441 \pm 0.065$ \\
\hline $22: 0$ & $0.010 \pm 0.001$ & $0.006 \pm 0.002$ & $0.019 \pm 0.007$ \\
\hline $22: 1 n-11$ & $0.095 \pm 0.007$ & $0.120 \pm 0.029$ & $0.187 \pm 0.029$ \\
\hline $22: 1 n-9$ & $0.039 \pm 0.005$ & $0.032 \pm 0.011$ & $0.075 \pm 0.014$ \\
\hline $22: 3 n-6$ & $0.019 \pm 0.001$ & $0.019 \pm 0.002$ & $0.022 \pm 0.001$ \\
\hline $22: 4 n-3$ & $0.158 \pm 0.007$ & $0.176 \pm 0.015$ & $0.172 \pm 0.012$ \\
\hline $22: 5 n-6$ & $0.283 \pm 0.027$ & $0.238 \pm 0.033$ & $0.254 \pm 0.013$ \\
\hline $22: 5 n-3$ & $0.310 \pm 0.030$ & $0.271 \pm 0.028$ & $0.290 \pm 0.010$ \\
\hline $22: 6 n-3$ & $8.311 \pm 0.745$ & $8.735 \pm 0.727$ & $5.945 \pm 1.724$ \\
\hline $24: 1 n-9$ & $0.017 \pm 0.002$ & $0.012 \pm 0.002$ & $0.020 \pm 0.002$ \\
\hline$\sum$ SFA & $5.792 \pm 0.453$ & $5.560 \pm 0.107$ & $7.246 \pm 0.137^{*}$ \\
\hline ¿MUFA & $4.200 \pm 0.441$ & $3.742 \pm 0.097$ & $7.859 \pm 0.212^{*}$ \\
\hline$\sum$ PUFA & $14.011 \pm 1.096$ & $15.621 \pm 0.922$ & $12.743 \pm 1.812$ \\
\hline$\sum n-3$ & $9.599 \pm 0.836$ & $9.959 \pm 0.701$ & $7.004 \pm 1.833$ \\
\hline$\sum n-6$ & $4.309 \pm 0.399$ & $5.540 \pm 0.367$ & $5.570 \pm 0.399$ \\
\hline
\end{tabular}

Fatty acid contents of liver were measured with a gas chromatography-flame ionization detector.

Values are means \pm SEM $\left(n=5,{ }^{*} p<0.05\right)$

Control: Control diet; Lys (-): Lysine-deficient diet; SFA: Saturated fatty acid; MUFA: Monounsaturated fatty acid; PUFA: Polyunsaturated fatty acid; $n-3: n-3$ fatty acid; n-6: n-6 fatty acid

Table 8: Fatty acid content $(\mathrm{mg} / \mathrm{g})$ in liver of rainbow trout from Lys-deficient trial.

shown that Lys-deficient feeding for about two months induced lipid level increment in the porcine skeletal muscle. Lipid increases in the liver and muscle caused by the Lys (-) diet in the present study agree with the results of these previous studies at the first glance. The present feeding period was, however, markedly different from those studies, and then we have considered that the underlying mechanisms responding to Lys-deficiency were probably different from each other. Although the mechanism underlying lipid increases during long-term Lysdeficiency have not been clarified, it is thought that an increase in the number and hypertrophy of adipocytes would lead to an increase in the intramuscular fat in Lys-deficiency in porcine [31], and that impaired lipid oxidation would be involved in fatty livers in Lys-deficient rats [32]. In this study, the increase in lipid content was probably due to more rapid response mechanisms, such as immediate changes in intracellular and/or intercellular signal transduction networks. In addition, the Lys (-) diet contained a larger amount of leucine than the control diet. Leucine is known to be an important amino acid for the activation of intracellular signaling pathways in mammals $[33,34]$. Previous study reported that leucine affects signaling pathways involved in energy metabolism as well as in fish [19]. The effects of other amino acid contents, such as leucine, will be investigated and discussed in our future physiological reports. Since Lys is a precursor of carnitine, Lys-deficiency possibly reduces carnitine content in fish body. A decrease in fatty acid oxidation in the muscle would partly contribute to the increase in lipid and fatty acid contents observed in this study. It is possible that various regulatory systems for lipid metabolism were affected by the Lys (-) diet in this study.

Lipid and n-3 LCPUFA contents of fish meat are important in determining its commercial value, and change depending upon factors such as water temperature, habitat environment, diet, and maturity. Previous studies on several species reported that the lipid content in fish muscles changes seasonally $[35,36]$, and that cultured fish meat tends to contain more lipids [37-39]. A high-fat diet causes an increase in the lipid content of fish tissues [40-42], and short-term fasting causes an increase of lipid content in the muscle [43]. However, feeds with higher lipid content are more expensive. In addition, long-term feeding of high-fat diets negatively influences fish health (e.g. hepatic failure), and short-term fasting causes a slight loss in body weight, resulting in an economic loss. Thus, methods for enriching fish meat with lipids and n-3 LCPUFAs, without economic or fish health problems, are in demand. The present study has demonstrated that short-term Lysdeficiency using a low-cost substitute for fish meal, corn gluten meal, successfully enriched fish meat with lipid and n-3 LCPUFAs.

Lipid and fatty acid contents in fish tissues are determined by lipid metabolism dynamics. The increase in lipid and n-3 LCPUFA contents in this study are likely to result from the following two systems: biosynthesis of fatty acids and uptake of dietary lipids.

First, the changes in liver fatty acid levels in this study imply that biosynthesis of fatty acids was enhanced in the liver of rainbow trout fed with Lys (-) diet. The liver is one of the main organs responsible for lipid biosynthesis in fish [44], and SFAs are produced through de novo synthesis from malonyl $\mathrm{CoA}$ and acetyl $\mathrm{CoA}$ with subsequent elongation. A portion of synthesized SFAs are desaturated to MUFAs. Previous studies have shown that 16:0, 18:0, 16:1, and 18:1 are mainly synthesized from acetate in Tilapia zillii [45], and that biosynthesis of fatty acid in fish is affected by dietary composition [46] and water temperature [47]. In this study, the total amounts of SFAs and MUFAs in the liver were significantly higher on Day 4 than on Day 0. This result suggests that the Lys (-) diet should enhance de novo synthesis and desaturation of fatty acids in the liver.

Secondly, it is likely that lipid accumulation derived from dietary lipids through Lys (-) feeding also contributes to the increase in lipid and n-3 LCPUFA contents. As stated above, fatty acid composition in fish tissues strongly reflects fatty acid composition in a fish diet [15]. In the liver tissues, a significant increase in 18:2n-6 content on Day 4 suggested that liver fatty acid content might reflect dietary fatty acid composition. Liver 20:2n-6 content on Day 2 was higher than that on Day 0 . This 20:2n-6 might derive from dietary intake or fatty acid conversion from other $n-6$ fatty acids, such as $18: 2 n-6$. Since $18: 2 n-6$ is a major fatty acid in both of the diets used in this study, the uptake of dietary n-6 fatty acids possibly relate to the increase in 20:2n-6 on Day 2. These results suggest that lipids and fatty acids from dietary lipids would be, at least in part, accumulated in the muscle tissues in the Lys $(-)$ group 
Citation: Yoshinaga H, Ushio H, Haga Y, Satoh S (2018) Pre-harvest Modulation of N-3 Long-chain Polyunsaturated Fatty Acids in Rainbow Trout Meat for Human Consumption. J Food Process Technol 9: 716. doi: 10.4172/2157-7110.1000716

Some n-3 LCPUFA and total n-3 fatty acid levels in muscle were higher on Day 4 than on Day 0 . Since rainbow trout are not able to desaturate fatty acids at the omega- 3 position, n- 3 fatty acid content in the muscle depends on the dietary intake. The accumulation of n-3 fatty acids was enhanced by short-term Lys deficiency, though there was no difference between fatty acid compositions in the control and Lys (-) diets. Therefore, it is likely that actively enhancing uptake of dietary n-3 LCPUFAs and the transport of lipids from other tissues to the muscle, contributes to an increase in n-3 LCPUFA content in fish meat during Lys-deficient feeding.

\section{Conclusion}

It was found that short-term Lys-deficient feeding induces an increase in lipid content and enrichment of $n-3$ fatty acids in rainbow trout muscle. These results are promising for the development of novel methods for producing fish meat containing a large amount of n-3 fatty acids. Moreover, our results imply that a short-term Lys-deficient feeding regimen might induce dynamic changes in the biosynthesis of fatty acids, and uptake of dietary lipids. In addition, there is also a possibility that the Lys-deficient feeding in this study affected the transport of fatty acids between organs. The underlying physiological and biomolecular mechanisms for these systems require further investigation. Further research is needed to determine optimal amino acid compositions of feed and/or feeding-terms to establish practical enrichment methods for various fish species.

\section{Acknowledgment}

This study was supported in part by a grant from the Japanese Ministry of Education, Culture, Sports, Science and Technology.

\section{References}

1. Ruxton C, Calder P, Reed S, Simpson M (2005) The impact of long-chain n-3 polyunsaturated fatty acids on human health. Nutr Res Rev 18: 113-129.

2. Carlson S, Colombo J, Gajewski B, Gustafson K, Mundy D, et al. (2013) DHA supplementation and pregnancy outcomes. Am J Clin Nutr 97: 808-815.

3. Bo $Y$, Zhang X, Wang Y, You J, Cui H, et al. (2017) The n-3 polyunsaturated fatty acids supplementation improved the cognitive function in the Chinese elderly with mild cognitive impairment: A double-blind randomized controlled trial. Nutrients 9: 54

4. Molfino A, Gioia G, Rossi Fanelli F, Muscaritoli M (2014) The role for dietary omega-3 fatty acids supplementation in older adults. Nutrients 6: 4058-4073.

5. Breslow J (2006) n-3 fatty acids and cardiovascular disease. Am J Clin Nutr 83: $1477 \mathrm{~s}-1482 \mathrm{~s}$

6. Weber P, Sellmayer A (1992) Cardiovascular effects of n-3 fatty acids. J Nutr Sci Vitaminol 38: 144-147.

7. Johnson M, Bradford C (2014) Omega-3, omega-6 and omega-9 fatty acids: implications for cardiovascular and other diseases. J Glycomics lipidomics 4: 2153-0637.

8. Wang C, Harris W, Chung M, Lichtenstein A, Balk E, et al. (2006) n-3 Fatty acids from fish or fish-oil supplements, but not alpha-linolenic acid, benefit cardiovascular disease outcomes in primary- and secondary-prevention studies: A systematic review. Am J Clin Nutr 84: 5-17.

9. Eslick G, Howe P, Smith C, Priest R, Bensoussan A (2009) Benefits of fish oil supplementation in hyperlipidemia: a systematic review and meta-analysis. Int J Cardiol 136: 4-16.

10. Miles $E$, Calder $P$ (2017) Can early omega-3 fatty acid exposure reduces risk of childhood allergic disease? Nutrients 9: 784

11. Kremmyda L, Vlachava M, Noakes P, Diaper N, Miles E, et al. (2011) Atopy risk in infants and children in relation to early exposure to fish, oily fish, or long-chain omega-3 fatty acids: A systematic review. Clin Rev Allergy Immunol 41: 36-66.

12. Enser M, Hallett K, Hewitt B, Fursey G, Wood J (1996) Fatty acid content and composition of English beef, lamb and pork at retail. Meat Sci 42: 443-456.
13. Trbovic D, Vranic D, Djinovic-Stojanovic J, Matekalo-Sverak V, Djordjevic $\mathrm{V}$, et al. (2012) Fatty acid profile in rainbow trout (Oncorhynchus mykiss) as influenced by diet. Biotech Anim Husbandry 28: 563-573.

14. Usydus Z, Szlinder-Richert J, Adamczyk M, Szatkowska U (2011) Marine and farmed fish in the Polish market: comparison of the nutritional value. Food Chem 126: 78-84.

15. Şener E, Yıldız M (2003) Effect of the different oil on growth performance and body composition of rainbow trout (Oncorhynchus mykiss W., 1792) juveniles. Turk J Fish Aquat Sci 3.

16. Andoh T (2007) Amino acids are more important insulinotropins than glucose in a teleost fish, barfin flounder (Verasper moseri). Gen Comp Endocr 151 308-317.

17. Plisetskaya E, Buchelli-Narvaez L, Hardy R, Dickhoff W (1991) Effects of injected and dietary arginine on plasma insulin levels and growth of pacific salmon and rainbow trout. Comp Biochem Phys 98: 165-170.

18. Navarro I, Rojas P, Capilla E, Albalat A, Castillo J, et al. (2002) Insights into insulin and glucagon responses in fish. Fish Physiol Biochem 27: 205-216.

19. Lansard M, Panserat S, Plagnes-Juan E, Dias K, Seiliez I, et al. (2010) L-leucine, L-methionine, and L-lysine are involved in the regulation of intermediary metabolism-related gene expression in rainbow trout hepatocytes. J Nutr 141: 75-80.

20. Ogino C (1980) Requirements of carp and rainbow trout for essential amino acids. Nippon Suisan Gakkaishi 46: 171-174.

21. Bligh E, Dyer W (1959) A rapid method of total lipid extraction and purification Can J Biochem Physiol 37: 911-917.

22. Kupke I, Zeugner S (1978) Quantitative high-performance thin-layer chromatography of lipids in plasma and liver homogenates after direct application of 0.5 -microliter samples to the silica-gel layer. J Chromatogr 146: 261-271.

23. Fiske C, Subbarow $Y(1925)$ The colorimetric determination of phosphorus. J Biol Chem 66: 375-400.

24. Bartlett G (1959) Phosphorus assay in column chromatography. J Biol Chem 234: 466-468.

25. Gomes E, Rema P, Kaushik S (1995) Replacement of fish meal by plant proteins in the diet of rainbow trout (Oncorhynchus mykiss): Digestibility and growth performance. Aquaculture 130: 177-186.

26. Mai K, Zhang L, Ai Q, Duan Q, Zhang C, et al. (2006) Dietary lysine requirement of juvenile Japanese seabass, Lateolabrax japonicus. Aquaculture 258: 535-542.

27. Aoyama Y, Ashida K (1972) Effect of excess and deficiency of individual essential amino acids in diets on the liver lipid content of growing rats. J Nutr 102: $1025-1032$

28. Kim J, Lee K, Kwon D, Bong J, Jeong J, et al. (2014) Severe dietary lysine restriction affects growth and body composition and hepatic gene expression for nitrogen metabolism in growing rats. J Anim Physiol Anim Nutr 98: 149-157.

29. Rathore R, Liaset B, Hevrøy E, El-Mowafi A, Espe M (2010) Lysine limitation alters the storage pattern of protein, lipid and glycogen in on-growing Atlantic salmon. Aquac Res 41: e751-e759.

30. Katsumata M, Kobayashi S, Matsumoto M, Tsuneishi E, Kaji Y (2005) Reduced intake of dietary lysine promotes accumulation of intramuscular fat in the Longissimus dorsi muscles of finishing gilts. Anim Sci J 76: 237-244.

31. Katsumata M (2011) Promotion of intramuscular fat accumulation in porcine muscle by nutritional regulation. Anim Sci J 82: 17-25.

32. Viviani R, Sechi A, Lenaz G (1966) Lipid metabolism in fatty liver of lysine- and threonine-deficient rats. J Lipid Res 7: 473-478.

33. Kimball S, Jefferson $L$ (2006) Signaling pathways and molecular mechanisms through which branched-chain amino acids mediate translational control of protein synthesis. J Nutr 136: 227s-231s.

34. Du M, Shen Q, Zhu M, Ford S (2007) Leucine stimulates mammalian target of rapamycin signaling in $\mathrm{C} 2 \mathrm{C} 12$ myoblasts in part through inhibition of adenosine monophosphate-activated protein kinase. J Anim Sci 85: 919-927.

35. Bandarra N, Batista I, Nunes M, Empis J, Christie W (1997) Seasonal changes in lipid composition of sardine (Sardina pilchardus). J Food Sci 62: 40-42.

36. Yildiz M, Şener E, Timur M (2008) Effects of differences in diet and seasonal 
Citation: Yoshinaga H, Ushio H, Haga Y, Satoh S (2018) Pre-harvest Modulation of N-3 Long-chain Polyunsaturated Fatty Acids in Rainbow Trout Meat for Human Consumption. J Food Process Technol 9: 716. doi: 10.4172/2157-7110.1000716

changes on the fatty acid composition in fillets from farmed and wild sea bream (Sparus aurata L.) and sea bass (Dicentrarchus labrax L.). Int J Food Sci Tech 43: $853-858$

37. Jahncke M, Hale M, Gooch J, Hopkins J (1988) Comparison of pond-raised and wild red drum (Sciaenops ocellatus) with respect to proximate composition, fatty acid profiles, and sensory evaluations. J Food Sci 53: 286-287.

38. Hatae K, Lee K, Tsuchiya T, Shimada A (1989) Textural properties of cultured and wild fish meat. Nippon Suisan Gakkaishi 55: 363-368.

39. Kunisaki N, Takada K, Matsuura H (1986) On the study of lipid contents, muscle hardness and fatty acid compositions of wild and cultured horse mackerel. Nippon Suisan Gakkaishi 52: 333-336

40. Galt N, Froehlich J, Meyer B, Barrows F, Biga P (2014) High-fat diet reduces local myostatin-1 paralog expression and alters skeletal muscle lipid content in rainbow trout, Oncorhynchus mykiss. Fish Physiol Biochem 40: 875-886.

41. Reinitz G (1983) Relative effect of age, diet, and feeding rate on the body composition of young rainbow trout (Salmo gairdneri). Aquaculture 35: 19-27.
42. Gelineau A, Corraze G, Boujard T, Larroquet L, Kaushik S (2001) Relation between dietary lipid level and voluntary feed intake, growth, nutrient gain, lipid deposition and hepatic lipogenesis in rainbow trout. Reprod Nutr Dev 41: 487-503.

43. Kaneko G, Shirakami H, Yamada T, Ide S, Haga Y, et al. (2016) Short-term fasting increases skeletal muscle lipid content in association with enhanced mRNA levels of lipoprotein lipase 1 in lean juvenile red seabream (Pagrus major). Aquaculture 452: 160-168.

44. Greene D, Selivonchick D (1987) Lipid metabolism in fish. Prog Lipid Res 26 53-85.

45. Kanazawa A, Teshima S, Imai K (1980) Biosynthesis of fatty acids in Tilapia zillii and the puffer fish. Mem Fac Fish, Kagoshima Univ 29: 313-318.

46. Dai W, Panserat S, Kaushik S, Terrier F, Plagnes-Juan E, et al. (2016) Hepatic fatty acid biosynthesis is more responsive to protein than carbohydrate in rainbow trout during acute stimulations. Am J Physiol Regul Integr Comp Physiol 310: R74-86.

47. Hazel J, Sellner P (1979) Fatty acid and sterol synthesis by hepatocytes of thermally acclimated rainbow trout (Salmo gairdneri). J Exp Zool 209: 105-114. 